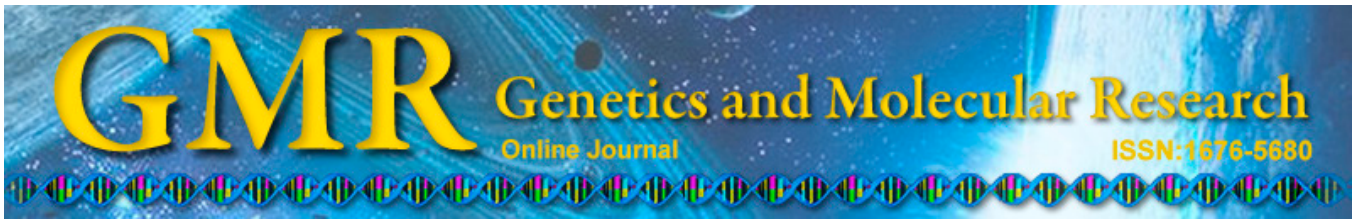

\title{
Successful treatment of pituitary abscess with intravenous antibiotics: a case report and literature review
}

\author{
H. Zhu, X.M. Gu, J. Hong and F.X. Shen \\ Department of Endocrinology and Metabolism, \\ The First Affiliated Hospital of Wenzhou Medical College, \\ Zhejiang Province, China \\ Corresponding author: F.X. Shen \\ E-mail: FeixiaSHENcn@126.com
}

Genet. Mol. Res. 13 (4): 10523-10528 (2014)

Received November 22, 2013

Accepted February 24, 2014

Published December 12, 2014

DOI http://dx.doi.org/10.4238/2014.December.12.14

\begin{abstract}
Pituitary abscess is a rare intrasellar infectious disease. It is usually treated with a combination of surgical drainage and intravenous antibiotics. We describe the case of a 38-year-old man with headache, fever, left earache, subsequent diabetes insipidus, and anterior pituitary insufficiency due to pituitary abscess, which was confirmed on the basis of clinical symptoms, laboratory examination results, and magnetic resonance imaging features. He was treated nonsurgically with intravenous antibiotics, with complete resolution of the pituitary abscess and recovery of pituitary function. Nonsurgical treatment may be an option for pituitary abscess.
\end{abstract}

Key words: Pituitary abscess; Antibiotics; Hypopituitarism 


\section{INTRODUCTION}

Pituitary abscess is a rare but life-threatening intrasellar infectious disease. Approximately 200 cases have been reported in the medical literature (Ciappetta et al., 2008), and the recommended management involves surgical drainage followed by antibiotic treatment (Vates et al., 2001; Dutta et al., 2006). Here, we report a case of pituitary abscess that was successfully treated with intensive intravenous antibiotic therapy, without surgical intervention.

\section{CASE REPORT}

A 38-year-old man with headache, fever, and left earache was diagnosed with acute left otitis media without effusion at the otolaryngology clinic in October 2010.

The highest body temperature recorded was $39.9^{\circ} \mathrm{C}$. He had received intravenous antibiotic therapy (levofloxacin $0.6 \mathrm{~g}$ /day) for 2 weeks and experienced periodic discharge from the left middle ear. His clinical symptoms improved soon afterwards but recurred several times. He was then treated irregularly with intravenous administration of penicillin $\mathrm{G}$ at a rural clinic.

The headache recurred in July 2011 and progressively worsened despite antibiotic therapy. He presented a high fever $\left(39.7^{\circ} \mathrm{C}\right)$, nausea, fatigue, polyuria (approximately 8000 $\mathrm{mL} /$ day), and polydipsia. He was admitted to the Department of Neurology with a possible intracranial infection. Findings of neurological examination were normal, and the signs of hypopituitarism were not remarkable.

The laboratory examination revealed a mildly elevated white blood cell (WBC) count ( $11.26 \times 10^{9} / \mathrm{L}$ with $80.1 \%$ neutrophils), an erythrocyte sedimentation rate of $31 \mathrm{~mm} / \mathrm{h}$ (reference range: $0-15 \mathrm{~mm} / \mathrm{h}$ ), and C-reactive protein of $12 \mathrm{mg} / \mathrm{L}$ (reference range: $0-8 \mathrm{mg} / \mathrm{L}$ ). The biochemical and immune indicators in the cerebrospinal fluid (CSF) were within the normal ranges. No organisms were detected in the blood or CSF in the culture after 7 days. Urinary specific gravity (1.001) and osmolality $\left(260 \mathrm{mOsm} \cdot \mathrm{kg} \cdot \mathrm{H}_{2} \mathrm{O}\right)$ were low, while the serum sodium concentration $(152 \mathrm{mM})$ was elevated. The results of the endocrine investigations were consistent with hypopituitarism (Table 1).

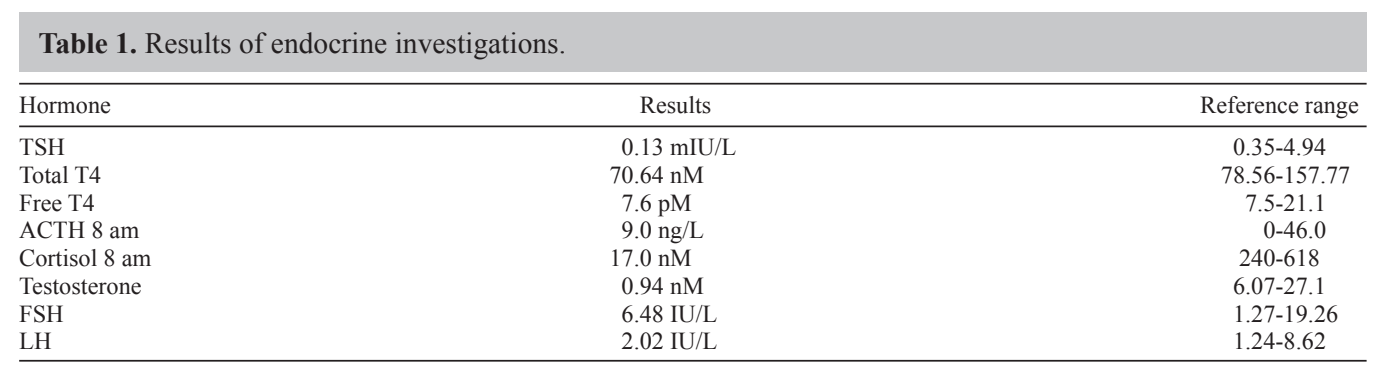

Magnetic resonance imaging (MRI) showed a bulging pituitary gland and pituitary stalk with inhomogeneous signals. The center of the pituitary gland was hypointense on T1weighted and hyperintense on T2-weighted images. On contrast-enhanced MRI, the lesion demonstrated relative non-enhancement but was lined with an irregularly enhanced rim. The margins of both cavernous sinuses were blurred and enhanced. A cystic mass was observed in the sphenoid sinus (Figure 1). 

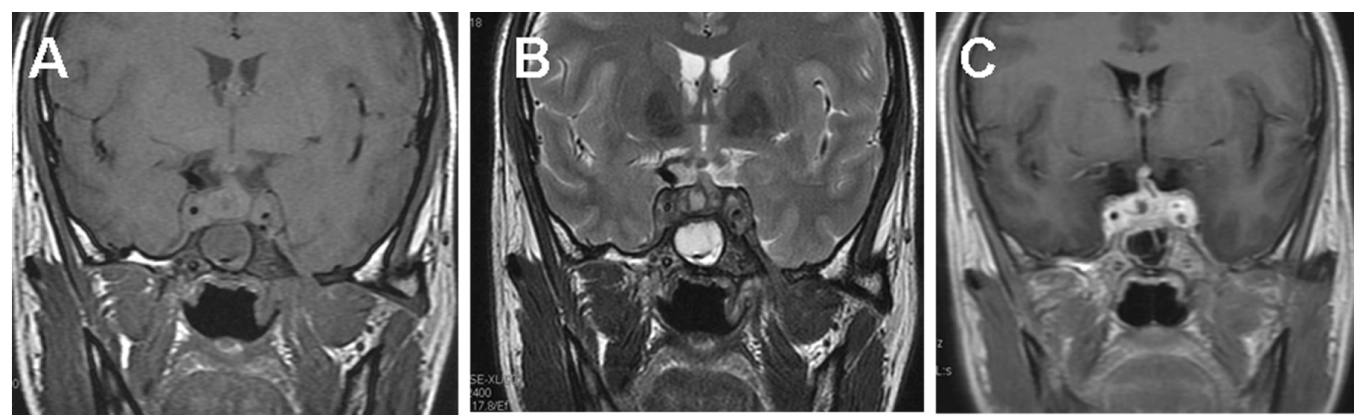

Figure 1. Imaging findings of pituitary abscess before medication on July 9, 2011. A. MRI showed a bulging pituitary gland and stalk and the center of pituitary gland was hypointense on T1-weighted images. There was a cystic mass in the sphenoid sinus. B. The center of pituitary gland was hyperintense on T2-weighted images. C. The lesion demonstrated relative non-enhancement lined with an irregular enhanced rim post-contrast. The margins of both cavernous sinuses were blurred and enhanced.

Following consultation with endocrinologists and neurosurgeons, a pituitary abscess was diagnosed based on the history, clinical presentation, panhypopituitarism, and imaging features. However, the patient refused to undergo surgical drainage and was transferred to the Department of Endocrinology. He was treated with intravenous antibiotics (ceftriaxone, 2 g, every $12 \mathrm{~h}$ ) and oral hormone replacement (prednisone $5 \mathrm{mg}$ at $8 \mathrm{am}$ and $2.5 \mathrm{mg}$ at $2 \mathrm{pm}$; thyroxine, $25 \mu \mathrm{g}$, every day; and desmopressin, $0.1 \mathrm{mg}$, every $8 \mathrm{~h}$ ).

After 1 week of therapy, his symptoms (fever, nausea, fatigue, polyuria, and polydipsia) resolved. The sizes of the pituitary gland, stalk, and cystic mass showed moderate regression following 18 days of treatment (Figure 2), and further improvement was achieved following 45 days of treatment (Figure 3), as shown in the follow-up MRI scan. Intravenous antibiotics (ceftriaxone, $2 \mathrm{~g}$, every $12 \mathrm{~h}$ ) were continued for 51 days, and he was discharged with continuous hormone replacement therapy in September 2011.

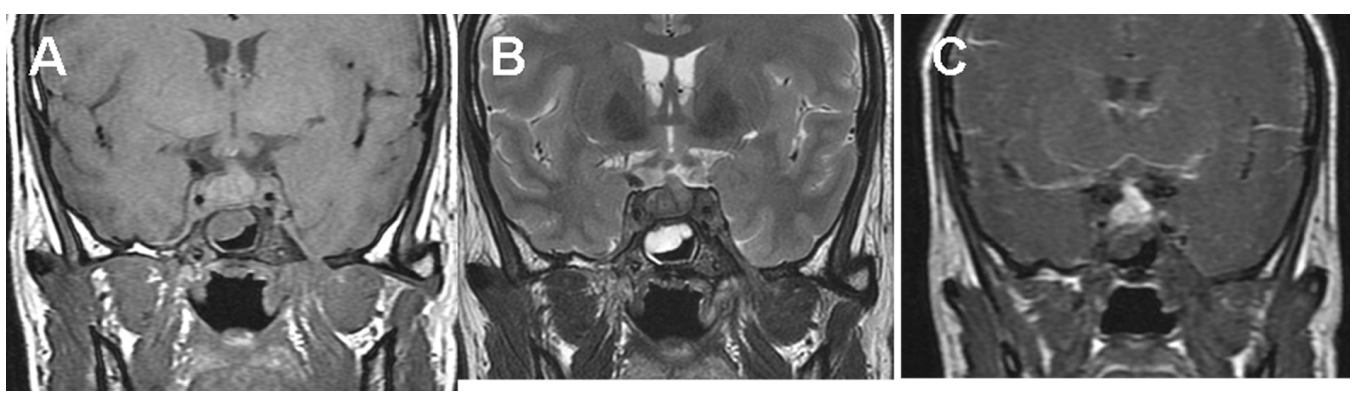

Figure 2. Imaging findings of pituitary after the 18 days of treatment: moderate regression in the size of pituitary lesion and the cystic mass in the sphenoid sinus. A. T1-weighted images. B. T2-weighted images. C. Enhancement images.

The patient was followed up $>1$ year after discharge. One month after discharge, his symptoms of diabetes insipidus had completely resolved, and the administration of desmo- 
pressin was ceased. Three months after discharge, the prednisone and thyroxine were also ceased. At 1 month without hormone replacement therapy, his endocrine function was normal: serum thyroid stimulating hormone, $2.35 \mathrm{mIU} / \mathrm{L}$ (reference range: $0.35-4.94$ ); thyroxine, $85.64 \mathrm{nM}$ (reference range: 78.56-157.77); adrenocorticotropic hormone at $8 \mathrm{am}, 40 \mathrm{ng} / \mathrm{L}$ (reference range: 0-46.0); cortisol at $8 \mathrm{am}, 251 \mathrm{nM}$ (reference range: 240-618); and testosterone, $17.17 \mathrm{nM}$ (reference range: 6.07-27.1). The follow-up MRI showed resolution of the pituitary lesions (Figure 4).

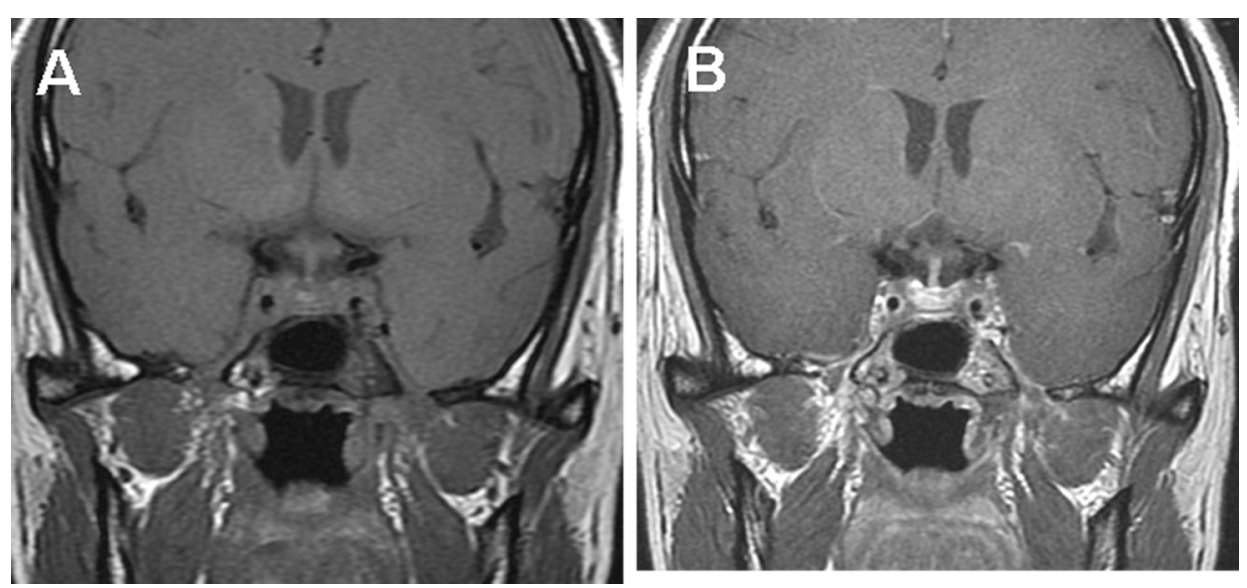

Figure 3. Imaging findings of pituitary after the 45 days of treatment: significant regression in the size of pituitary lesion with disappearance of the cystic mass in the sphenoid sinus. A. T1-weighted images. B. T2-weighted images.

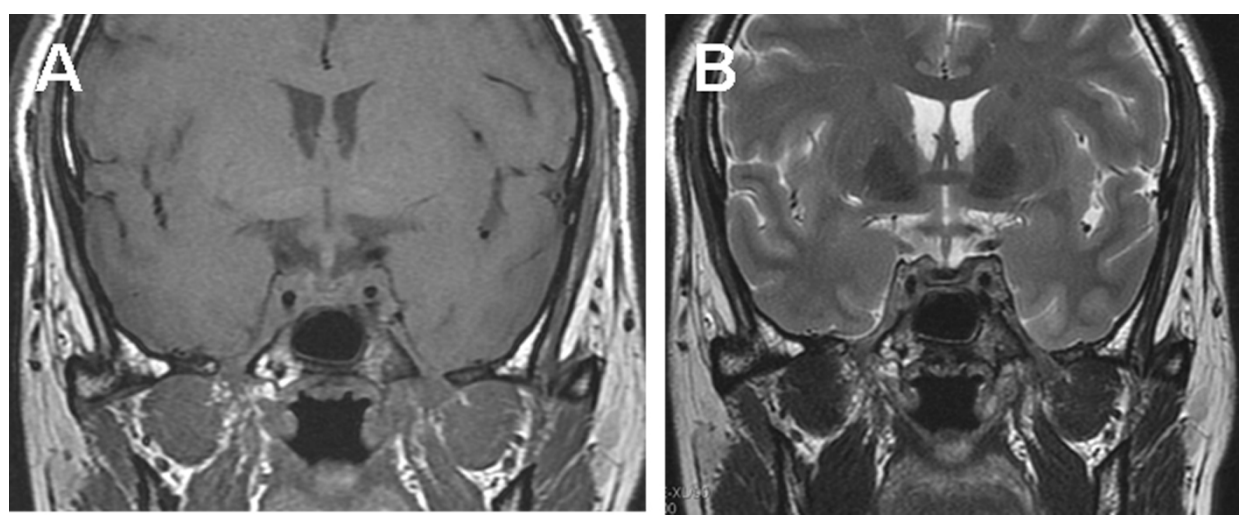

Figure 4. Imaging findings of pituitary 3 months after ceasing medications: complete resolution of pituitary lesion. A. T1-weighted images. B. T2-weighted images.

\section{DISCUSSION}

Pituitary abscess is a rare condition and is difficult to diagnose without obtaining an operative specimen. This is primarily because the presentation is different from those of other common infectious diseases. Half of the patients do not have underlying risk factors for pituitary 
infection, such as bloodstream infections, direct extension from a focus around the intrasellar region, or disease following an intrasellar tumor or post-pituitary operation (Tekkök et al., 2001). Furthermore, systemic signs of inflammation, such as fever and leukocytosis, are reported in only $24-33 \%$ of patients with a pituitary abscess (Vates et al., 2001; Dalan and Leow, 2008).

In the present case, the patient had obvious infectious features including a high fever and elevated peripheral WBC and neutrophil counts. Moreover, the patient's symptoms recovered after administration of antibiotic therapy, which is consistent with an infectious disease process. The patient had acute left otitis media, and the MRI showed a cystic mass in the sphenoid sinus. These findings indicated that direct invasion from the left otitis media might have caused the formation of a sphenoid sinusitis, which is one of the causes of pituitary abscess.

We consider the clinical symptoms (headache and diabetes insipidus), laboratory examination results (hypopituitarism), and MRI findings (sellar cystic mass with an enhanced rim), which are the diagnostic features suggestive of a pituitary abscess (Liu et al., 2011), in addition to the response to antibiotic therapy with resolution of symptoms and the pituitary lesion on imaging as evidence for a case of pituitary abscess even without surgical confirmation.

Surgical drainage is the standard treatment for a pituitary abscess. The transsphenoidal approach is strongly recommended; however, craniotomy is appropriate when the abscess is exclusively suprasellar or significant evacuation is considered difficult (Dutta et al., 2006). Although the operation is efficacious, it is still an invasive and traumatic procedure. Complications of surgery include meningitis, cerebritis, vascular injury, and CSF leakage (Zhang et al., 2012). The incidence of complications is decreasing with the advancement in medical techniques. However, they cannot be completely avoided. The operation could also increase the risk of or delay the recovery from anterior pituitary insufficiency and diabetes insipidus. Liu et al. (2011) reported that only 8 of 30 patients (including 3 patients who had normal preoperative pituitary function) achieved normal pituitary function following surgery. The remaining patients continued to require hormone replacement therapy, and 6 of the 21 patients with preoperative diabetes insipidus required postoperative desmopressin acetate. Insufficient endocrinological recovery has also been reported in other case series (Vates et al., 2001; Ciappetta et al., 2008; Dalan and Leow, 2008). Surgery can also result in secondary destruction of the pituitary gland.

Since the first report by Dechambenoit et al. (1993) of pituitary abscess treatment using medications, 5 cases of successful recovery by antibiotic therapy alone have been reported in the literature (Kaur et al., 2005; Uchida et al., 2008; Liu et al., 2011). Compared to surgical management, these patients with pituitary abscess treated conservatively with medication alone experienced a full recovery. In our case, the symptoms of fever and headache recovered 1 week after administration of antibiotics and hormone replacement. The pituitary lesions fully resolved on MRI imaging, and the diabetes insipidus and anterior pituitary insufficiency were also subsequently resolved.

Previous reports have described the role of a whole spectrum of microbiological agents in pituitary abscess, including Gram-positive cocci, Gram-negative bacilli, fungi, amoebae, and yeast (Becker Jr. et al., 1980; Ramos-Gabatin and Jordan, 1981; Heary et al., 1995; Jain et al., 1997; Vates et al., 2001). Broad-spectrum antibiotic therapy should be the best choice for patients with pituitary abscess. At the same time, there should be adequate distribution of the antibiotics to the brain tissue. In fact, Zhang et al. (2012) strongly recommended meningitislevel doses of a third-generation cephalosporin. The pathogen in the present case was not identified. However, ceftriaxone (a third-generation cephalosporin) at a dose of $4 \mathrm{~g} / \mathrm{day} \mathrm{dem}-$ onstrates excellent distribution to brain tissue and is also an appropriate selection for treatment 
of sphenoid sinusitis. Because cases with treatment of pituitary abscess by medication alone are rarely reported, the required duration of antibiotics has not been well defined. According to previous cases (Dechambenoit et al., 1993; Kaur et al., 2005; Uchida et al., 2008; Liu et al., 2011), >4 weeks of intravenous antibiotic administration is essential in patients with pituitary abscess.

In our opinion, medical treatment without surgery may be an option for some cases of pituitary abscess because it is efficacious and eliminates surgical trauma and complications. However, pituitary abscess is a potentially life-threatening disease, and the patient must be closely monitored. If significant improvement is absent or if the patient's condition deteriorates, surgery is urgently required.

\section{Conflicts of interest}

The authors declare no conflict of interest.

\section{ACKNOWLEDGMENTS}

The authors warmly thank Dr. Elizabeth Chua (Department of Endocrinology \& Metabolism, Royal Prince Alfred Hospital, Australia) for her helpful insights and critical review of the manuscript.

\section{REFERENCES}

Becker GL Jr, Knep S, Lance KP and Kaufman L (1980). Amebic abscess of the brain. Neurosurgery 6: 192-194.

Ciappetta P, Calace A, D'Urso PI and De Candia N (2008). Endoscopic treatment of pituitary abscess: two case reports and literature review. Neurosurg. Rev. 31: 237-246.

Dalan R and Leow MK (2008). Pituitary abscess: our experience with a case and a review of the literature. Pituitary 11: 299-306.

Dechambenoit G, Datie A, Grunitzky EK, Ba Zeze V, et al. (1993). Pituitary abscess, treated by medication. Rev. Neurol. 149: 567-571.

Dutta P, Bhansali A, Singh P, Kotwal N, et al. (2006). Pituitary abscess: report of four cases and review of literature. Pituitary 9: 267-273.

Heary RF, Maniker AH and Wolansky LJ (1995). Candidal pituitary abscess: case report. Neurosurgery 36: 1009-1013.

Jain KC, Varma A and Mahapatra AK (1997). Pituitary abscess: a series of six cases. Br. J. Neurosurg. 11: 139-143.

Kaur A, Agrawal A and Mittal M (2005). Presumed pituitary abscess without infectious source treated successfully with antibiotics alone. J. Neuroophthalmol. 25: 185-188.

Liu F, Li G, Yao Y, Yang Y, et al. (2011). Diagnosis and management of pituitary abscess: experiences from 33 cases. Clin. Endocrinol. 74: 79-88.

Ramos-Gabatin A and Jordan RM (1981). Primary pituitary aspergillosis responding to transsphenoidal surgery and combined therapy with amphotericin-B and 5-fluorocytosine: case report. J. Neurosurg. 54: 839-841.

Tekkök IH, Akpinar G and Gungen Y (2001). Abscess formation within a pituitary adenoma: report of a case and review of the literature. Infect. Dis. Clin. Pract. 10: 367-373.

Uchida Y, Tsuchimochi N, Oku M, Fujihara N, et al. (2008). Successful treatment of pituitary abscess with oral administration of sparfloxacin. Intern. Med. 47: 1147-1151.

Vates GE, Berger MS and Wilson CB (2001). Diagnosis and management of pituitary abscess: a review of twenty-four cases. J. Neurosurg. 95: 233-241.

Zhang X, Sun J, Shen M, Shou X, et al. (2012). Diagnosis and minimally invasive surgery for the pituitary abscess: a review of twenty nine cases. Clin. Neurol. Neurosurg. 114: 957-961. 